
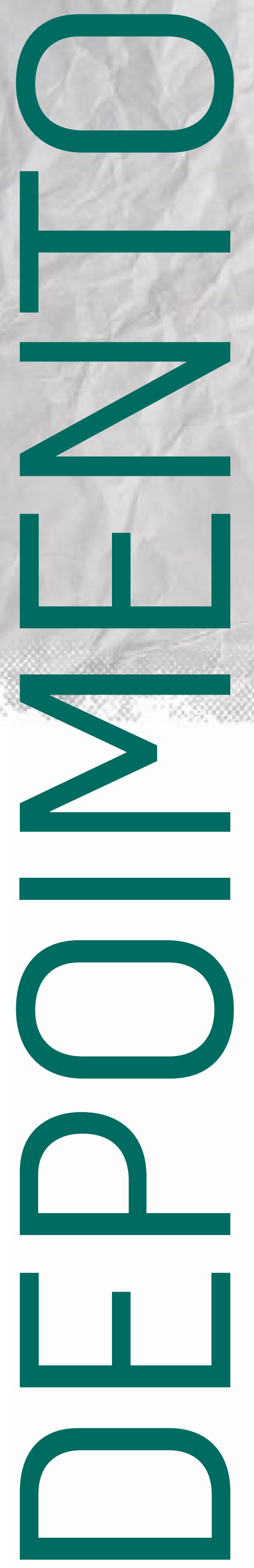


\section{A experiência de liderar o coletivo Movimento Elefantes, um grupo de big band de São Paulo}

\section{The experience of leading the Movimento Elefantes collective, a São Paulo big band group}

\section{La experiencia de liderar el colectivo Movimento Elefantes, un grupo de big band de São Paulo}

\section{Marco Antonio Pinheiro da Silveira ${ }^{1}$ Denis Rodrigo Garces Lopes²}

0 coletivo Movimento Elefantes (ME), de São Paulo, consiste num conjunto de big bands que se juntaram para realizar ações em conjunto. As big bands são grupos musicais relativamente grandes que têm uma configuração baseada em instrumentos de sopro, sendo originalmente cinco saxofones, quatro trompetes e quatro trombones, porém há muitas variações. O Movimento Elefantes foi constituído em 2009 por dez bandas: Banda Jazzco; Banda Savana; Banda Urbana; Big Band da Santa; Grupo Comboio; Projeto Coisa Fina; Orquestra HB; Projeto Meretrio; Reteté Big Band; e Soundscape Big Band.

As novas dinâmicas da produção e publicação de notícias demandam novas soluções para a necessária e indispensável tarefa de analisar a mídia e informar às organizações que detêm marcas expostas ao público sobre fontes e temas que mais as afetam, em que intensidade e com que consequências, positivas ou negativas.

Vinícius Pereira foi o catalisador e um dos fundadores do coletivo. Segundo ele, a ideia de constituir o grupamento se deu a partir de uma experiência vivida por ele em Caracas, em 2009, quando era integrante da banda Projeto Coisa Fina. Essa banda foi convidada a tocar na Venezuela com o trio Kapicua. Quando estava em Caracas, participando de uma pequena turnê, tomou conhecimento de um movimento coletivo de música instrumental chamado La Mau (La Movida Acústica Urbana). Esse coletivo venezuelano era composto por seis grupos, que trabalhavam com música urbana e autoral e se uniram para formar uma rede de relacionamentos e trocar suas experiências, conhecimentos e tudo mais que pudessem compartilhar.

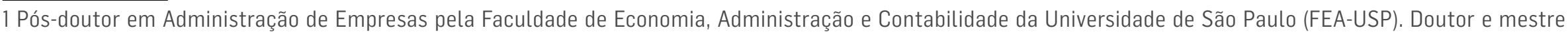

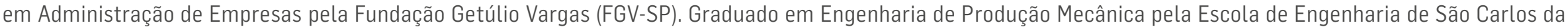

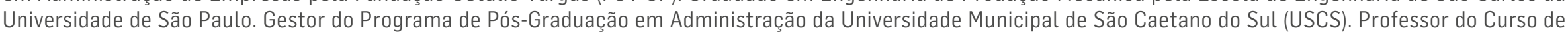

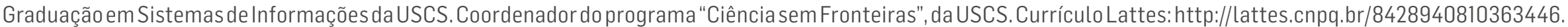
E-mail: marco.pinheiro@uscs.edu.br.

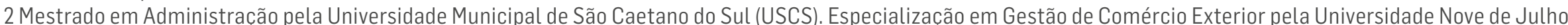

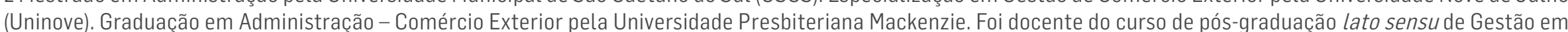

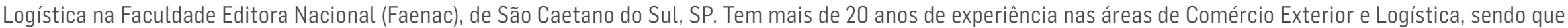

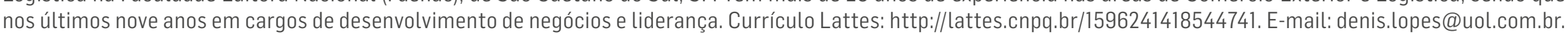


Vinicius Pereira foi o coordenador do ME até 2013, quando se afastou da coordenação, para buscar novas experiências, além do fato de, segundo ele, ter se cansado de ser responsável por quase todas as tarefas no ME. Conforme relata 0 atual coordenador, o músico Amador Bueno, as buscas de oportunidades estão também concentradas principalmente na sua figura, apesar de haver participação do pessoal do staff. As reuniões mensais do grupo têm ocorrido no Bar Central das Artes, e após cada reunião uma banda se apresenta.

Em março de 2014, Vinicius Pereira nos deu o depoimento que segue, cujo foco principal foi sua experiência como coordenador e as trocas que realizou durante ela.

"Não faço parte mais do coletivo Movimento Elefantes nem do Projeto Coisa Fina. Foi uma ruptura necessária. Eu precisava parar de trabalhar ali, porque eu já não me sentia pleno com o que era minha motivação inicial - viver uma experiência de coletivo. Eu me frustrei. Quando iniciamos o projeto, eu já sabia que ia ser difícil e que pouca gente ia se envolver. Eu sou uma figura centralizadora e com isso eu colaborei com a minha própria tragédia, trazendo pra mim tudo, centralizando um monte de ações, principalmente de produção, que é uma coisa que é chata, que nós, músicos, não gostamos de fazer. Mas, como as outras pessoas às vezes não faziam bem essas tarefas, e como eu sabia que podia fazer, eu tomava aquilo pra mim. Então o processo de coletividade, de produção coletiva ficava menor.

Para mim, o mais legal é viver os processos coletivos. Eu gosto mesmo é de colocar as minhas ideias, ouvir a ideia dos outros e transformar coisas o tempo todo, viver uma vida em constante transformação. É um processo de troca e eu quero viver essa experiência de troca, trocar experiências para crescer.

O coletivo Movimento Elefantes era algo muito grande, com muitas bandas e muitas pessoas dispersas. Eu fiz muitas amizades e conheço a maioria dos músicos do ME. 0 Emiliano, da Banda Meretrio, escreveu composições para a minha banda e tivemos uma troca de informações muito legal, aprendi muito musicalmente e artisticamente. Também toquei muito e troquei muitas experiências com o Rui (da Banda Urbana) e Amador Bueno (da Jazzco).

A experiência no ME poderia permitir que seus membros experimentassem o que se costuma chamar de influências musicais: a estética do som, o ethos do som, o estilo recorrente no momento, a moda, o jeito de tocar. Não havia uma regra muito definida para entrada e saída de bandas no ME. A gente conversava com as pessoas e plantava a ideia e no boca-aboca um chamava o outro.

A experiência do coletivo Movimento Elefantes deixou muito claro que quanto mais gente, mais difícil essa experiência de trocas mais profundas. E, como eu já disse, sempre espero que as experiências de trocas sejam realmente transformadoras. Porém, no ME também havia relacionamentos com pessoas que não eram abertas, e isso cansava demais. É trocar com pessoas que ofereçam abertura para isso, é legal ter homogeneidade, mas também é importante ter a diversidade. É difícil lidar com um grande número de pessoas, pois algumas são muito fechadas. Eu acho que as pessoas de fato estão sempre muito ocupadas, não têm tempo para nada. Para alguns, o Coletivo Movimento Elefantes era mais um projeto e não o projeto principal. O panorama desse tipo de músico é: ou ele trabalha para alguém ou ele trabalha para si. Eles normalmente fazem parte de vários projetos ao mesmo tempo, vivem o tempo todo correndo atrás do imediato, não veem a big band ou o Coletivo Movimento Elefantes como algo seu, não vestem a camisa.

Temos que lembrar que existe o lado comercial das bandas. Mas, se o objetivo primeiro da banda é estar no mercado, ser um grande ator no mercado, acredito que a haverá dificuldade de ela ter uma qualidade artística. Eu estou interessado em 
arte, de gente fazendo coisa profunda, aberta. Então, se o foco da banda é conquistar o mercado, não é um foco que me interessa. Isso não significa que a gente não deve estar atento ao mercado e se preparar para ele, mas a prioridade não é 0 mercado, a prioridade é a arte.

No início do coletivo Movimento Elefantes, todos os participantes trabalhavam juntos, mas com o tempo as coisas ficaram somente comigo. Tivemos diversas temporadas em vários lugares: Centro Cultural, Museu da Casa Brasileira, Sesc Pinheiros, Teatro da Vila, Sesc Santo André. A experiência permitia que as bandas se apresentassem, ainda que com cachê baixo, mas trabalhando. Era bom para as bandas fazerem parte de uma iniciativa que impulsionava seu trabalho. Havia infinitos formatos possíveis para propiciar a contratação das bandas para temporadas. Exemplos: Virada cultural (um dia só), Sesc Pinheiros (uma semana), Museu da Casa Brasileira (uma banda por mês), Teatro da Vila (toda semana). Aliás, o Teatro da Vila era a nossa residência (com apresentação de uma banda toda segunda-feira).

No caso das residências, como o Bar Central das Artes, residência atual do ME, as bandas não recebem cachê. Funciona como uma contribuição que as bandas dão para o Movimento, que equivale a uma mensalidade.

Resumindo minha experiência com o coletivo Movimento Elefantes, posso dizer que para mim foi ótima. Aprendi muito, tive trocas muito boas, fiz amigos, fiz muita produção executiva e engordei meu portfólio, tive muitas ideias. Para mim individualmente foi ótimo. Mas, a partir de um certo momento, me desgastei muito e passei a não querer mais e comecei a me cansar. Pensando socialmente, esse projeto foi uma experiência de vida para muitas pessoas. Quanto ao futuro do Elefantes, o que eu quero é que eles consigam viver uma experiência de troca boa. E fico aqui desejando, emanando para eles.

O ME difundiu as bandas de fato, conseguiu uma certa integração, conseguiu uma ótima integração em relação aos subs (músicos substitutos), a articulação dos músicos entre as bandas ficou muito mais dinâmica. As pessoas se conheceram melhor, graças a uma experiência de conexão de redes, pelo simples fato de duas bandas tocarem no mesmo espaço. Esse tipo de experiência foi bom para todos, colocando todos em rede. Porém, o quão profunda é a experiência em rede depende unicamente de cada um através do seu próprio envolvimento. No meu caso, foi uma coisa absurda para minha vida, porque eu estava envolvido até o último fio de cabelo. Então, cada um aproveita o que pode e o que quer."

Aqui termina o depoimento que Vinicius Pereira nos deu. 